Focussed on "Crack Paths"

\title{
Stress Intensity Factor Equations for the Evolution of Surface and Corner Cracks to Through Cracks
}

\author{
Antonio Carlos de Oliveira Miranda, Rafael Marques \\ University of Brasilia, Brasil \\ acmiranda@unb.br,marquessilvarafael15@gmail.com
}

\author{
Marco Antonio Meggiolaro, Jaime Tupiassú Pinho de Castro \\ Pontifical Catholic University of Rio de Janeiro, Brasil \\ meggi@puc-rio.br,jtcastro@puc-rio.br
}

\begin{abstract}
Part-through surface or corner 2D cracks are commonly found in structural components, even because practically all fatigue cracks tend to start this way. It is a reasonable hypothesis to model them assuming the shape of their 2D fronts can be approximated by an elliptical arc, as supported by many fractographic observations. However, their transition to a 1D throughcrack, an important issue in many practical applications, is normally not properly addressed in fatigue life predictions. Although experimental results reveal that the frontiers of surface cracks essentially retain their elliptical shape as they gradually grow into an $1 \mathrm{D}$ through-crack, it is usual to assume they are immediately transformed into an 1D through-crack when their depth reaches the cracked component thickness. This crude approximation may create a large jump in stress intensity values, leading to excessively conservative fatigue crack growth predictions; or else, the crude shape jump hypothesis might induce false overload events that can much affect fatigue crack growth retardation models, leading to inadmissible non-conservative life predictions. To minimize such problems, an improved model to describe the transition of 2D surface cracks to $1 \mathrm{D}$ through-cracks is proposed and verified by crack propagation tests in two different materials, 4340 steel and polycarbonate (PC). Moreover, fatigue life predictions based on this improved model are compared with experimental results obtained with these two materials.
\end{abstract}

KEYWORDS. 2D-1D crack transition; SIF equations; fatigue analysis.

\section{OPEN ACCESS}

Citation: de Oliveira Miranda, A.C., Marques, R., Meggiolaro, M.A., Pinho de Castro, J.T., Stress Intensity Factor Equations for the Evolution of Surface and Corner Cracks to Through Cracks, Frattura ed Integrità Strutturale, 48 (2019) 611-629.

Received: 29.11.2018

Accepted: 30.01 .2019

Published: 01.04.2019

Copyright: (C) 2019 This is an open access article under the terms of the CC-BY 4.0, which permits unrestricted use, distribution, and reproduction in any medium, provided the original author and source are credited.

\section{INTRODUCTION}

$\mathrm{F}$ atigue cracks tend to nucleate on surfaces, usually at a notch tip whose stress concentration effects cannot be neglected in fatigue analyses. Most fatigue cracks initiate and initially grow in $2 \mathrm{D}$ with a crack front that can be approximated by an elliptical arc, see e.g. the ASM Fractography Handbook for plenty of evidence to support this 
claim [1]. In fact, even when fatigue cracks initiate from a far-from-elliptical notch tip, they quickly tend to an approximately elliptical front, as shown by the crack that departs from an elongated rectangular notch illustrated in Fig. 1.

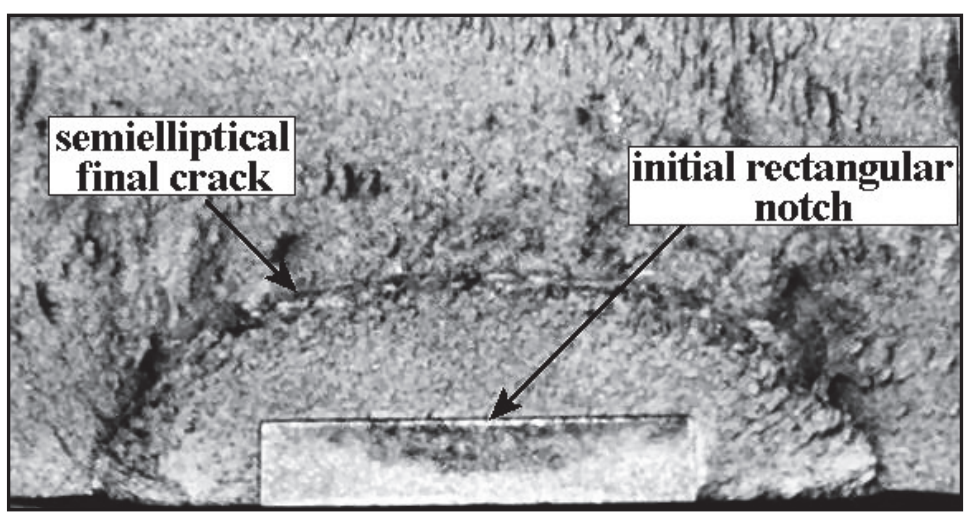

Figure 1: Crack that initiated from a rectangular notch, but changed to an elliptical-like front within a short distance from it [2].

Neglecting short crack issues (which, however, may be important in many practical cases, as studied e.g. in [3-4]), fatigue crack growth (FCG) lives can usually be well estimated by integrating the FCG $d a / d N \times \Delta K$ curve of the material, where $d a / d N$ is the FCG rate caused by the stress intensity factor (SIF) range $\Delta \mathrm{K}$. Such calculations apply in simple memory-free constant amplitude loading cases. Since FCG curves can be properly measured following standard ASTM procedures, then well-known numerical integration techniques can be used to perform fatigue life predictions of cracked components once the appropriate $\Delta \mathrm{K}$ is known for the problem in hand, no matter how complex the SIF expression is.

Most fatigue cracks tend to grow in three distinct phases. They usually initiate at a surface as a 2D crack and grow in $2 \mathrm{D}$ up to reaching the piece thickness. Then they make a gradual transition from their initial 2D shape to a through $1 \mathrm{D}$ crack, and eventually propagate until the final fracture with a crack front shape that can be treated as 1D (albeit they cannot have a straight front, as discussed in [5]). The weak modeling link in this process is the 2D to $1 \mathrm{D}$ transition, since there are no standard SIF solutions for this problem, even though there are plenty of handbook expressions to evaluate SIFs for many geometries in which the cracks grow in a single 1D direction, as well as various classic solutions for 2D cracks that propagate maintaining elliptical crack fronts. For practical reasons, these solutions assume an elliptical crack front shape to avoid having to model the free surface singularity [6].

There are classic analytical expressions for quantifying the SIF of elliptical 2D cracks under combined tension and bending, most obtained by proper fitting 3D finite element (FE) solutions. These expressions are complex and difficult to use for quick estimates, but they can be relatively easily integrated by standard numerical methods. For instance, if these cracks occur in a plate of width $w$ (or $2 w$, if the subsequent through-crack has two tips) and thickness $t$, their SIF range $\Delta K$ is a function of the stress range $\Delta \sigma$, of the ratios $a / c, a / t$ and $c / w$, and of an angle $\theta$ defined in Fig. 2, because their SIF values vary from point to point along their fronts [7-10]:

$$
\Delta K=\Delta \sigma \cdot \sqrt{(}(\pi a) \cdot f_{\theta}(a / c, a / t, c / w)
$$

where $f_{\theta}$ is a crack shape function and $a$ and $c$ are the ellipsis semi-axes.

It usually is a quite reasonable approximation to assume that real $2 \mathrm{D}$ crack fronts have a near elliptical shape, but this is not enough to model their FCG behavior and to make FCG life predictions. It is also necessary to assume that the successive fronts of such 2D cracks retain the elliptical shape but may change their $a / c$ ratio at every load cycle, because their SIFs vary along the crack front. Based on the maintenance of an elliptical geometry, the basic modeling idea for 2D FCG predictions is to couple the crack growth in the depth (a) and surface width ( $2 c$ for surface and $c$ for corner cracks) directions at every load event, as studied e.g. in [10].

However, the transition behavior from a corner or surface flaw into a through-crack usually is not even addressed when modeling them. For example, consider a surface crack as in Fig. 2 (left). If the cracked plate material is tough enough and if $2 w>>2 c$, this surface crack can propagate until reaching the back surface of the plate. Then there is a transition region until the $2 \mathrm{D}$ crack can be considered a $1 \mathrm{D}$ through crack, whose traces are nearly equal both on the front and on the back face of the plate. 


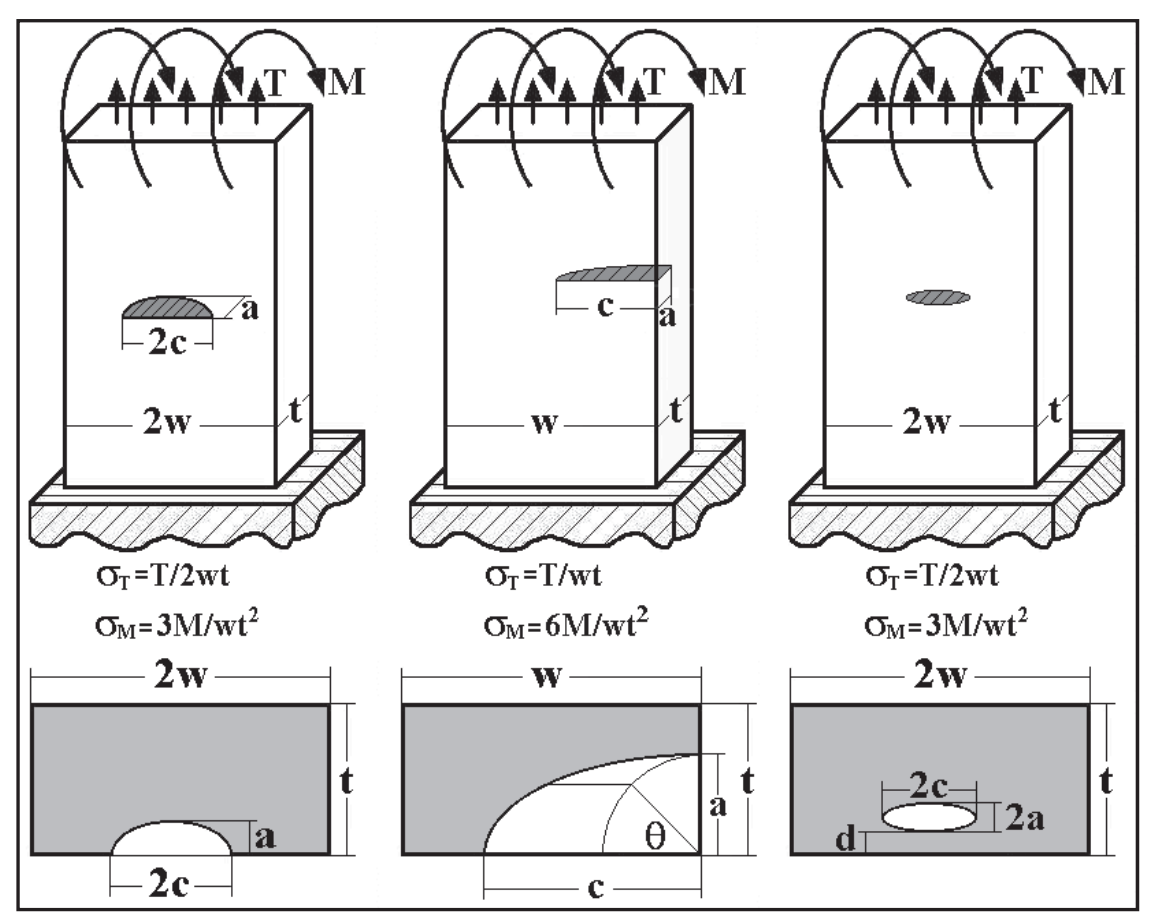

Figure 2: Surface semi-elliptical, corner quarter-elliptical, and internal elliptical cracks [10].

There are authors that claim that, for fatigue life estimation purposes, it can be assumed that surface cracks immediately transform into through-cracks as their depth a reaches the thickness $t$ at the back surface of the cracked component [11]. An example to justify this simplification in the FCG transition is presented by Grandt et al. [12-13]. They studied a crack that grew on a double-T cross-section beam under bending. Theirs initially $2 \mathrm{D}$ quarter-elliptical crack propagated twodimensionally through the lower corner of the section until it almost penetrated the inner rear face of the section at 60,923 cycles. Then, the crack increased rapidly and cut the entire leg in only 80 more cycles. Hence, the 2D to 1D transition cycles could be neglected based on a supposed "catch up effect" [12], assuming the crack front at the back surface experiences a much higher SIF (and so a much faster FCG rate) than at the front surface, tending to straighten its profile. However, this approach creates a discontinuity in the calculated SIF values, often causing the crack growth prediction to be excessively conservative, because such a simplification can behave like if it was an overload that causes subsequent FCG delays in most numerical FGC prediction codes, see e.g. [10,14].

Moreover, other experimental results reveal that quasi-elliptical surface 2D flaws may not immediately transform into through-cracks. Fawaz e.g. studied the shape of fatigue crack fronts that started from a hole in Al 2024-T3 Alclad thin plates with thickness $t=1.6 \mathrm{~mm}$, loaded under combined tension and bending [15]. He found that his cracks essentially retained their elliptical shape as they gradually grew into through-cracks. Even though this detailed experiment indicates a need for it, no closed-form SIF-solution is available for through-cracks with such oblique fronts. Some approximations have been suggested based on the boundary element method [8], however they do not account for the component width effect, a major limitation on practical applications.

A simplified model for the 2D-1D crack front transition was proposed by Johnson a long time ago [16]. According to him, after the crack depth reaches the specimen thickness $t$, the crack can be assumed to keep its elliptical shape in the transition zone. Johnson used an adaptation of the surface (2D) stress intensity factor (SIF) expressions described by Hall et al. [17] to model the surface crack transition. However, Johnson's original approach may be inaccurate, since it uses overly simplified the SIF expressions for surface cracks, without considering the effect of the specimen width $2 w$ and the variation of the front surface effect (assumed constant and equal to 1.1). In addition, it does not guarantee continuity of the SIF expression $K_{I}(c)$ in the width direction between the transitioning period and the $1 \mathrm{D}$ crack growth regimen. This problem is particularly deceiving when FCG retardation models are considered in fatigue life calculations. If the considered SIF equation calculates a smaller value for the through crack than for the transitional range, the retardation model may consider the larger SIF as an overload, delaying its subsequent 1D growth. Therefore, when considering load interaction models, Johnson's approach may predict FCG retardation even under constant amplitude loading, resulting in non-conservative fatigue life predictions. 
Castro and Meggiolaro [10] proposed in their 2016 book improved equations for 2D-1D crack transitions, which are inspired on Johnson's approach but use much improved Newman-Raju's solutions for the 2D crack SIFs [18-22]. However, their proposed equations have not been properly checked by experimental data. To verify them, in this paper 2D-1D FCG transitions are measured in two different materials, 4340 steel and polycarbonate (PC), in order to present suitable crack size and shape data, and the corresponding numbers of cycles spent in the 2D-1D transition zones, as discussed in the following. These studies were done only for plate-like geometries. Some authors have worked with different geometries, like the pipes studied in [23-24], for example.

\section{IMPROVED MODELS FOR THE TRANSITION FROM SURFACE TO THROUGH CRACKS}

$\mathrm{N}$ ewman-Raju's equations are adapted to model the transition from surface semi-elliptical or corner quarter elliptical $2 \mathrm{D}$ cracks to through-the-thickness $1 \mathrm{D}$ cracks. In addition to the effects of the back face magnification and crack shape parameter, Newman-Raju's expressions also model the specimen width and front surface effects. To model the $2 \mathrm{D} / 1 \mathrm{D}$ transition zone, the basic hypothesis of ellipsoidal geometry preservation is assumed. Therefore, as illustrated in Fig. 3 [10], Johnson's criterion $c^{\prime}=0.9 \cdot c$ for the end of the $2 \mathrm{D} / 1 \mathrm{D}$ transition zone is equivalent to

$$
a^{\prime}=t / \sqrt{1-\left(c^{\prime} / c\right)^{2}}=t / \sqrt{1-0.9^{2}} \cong 2.3 t
$$

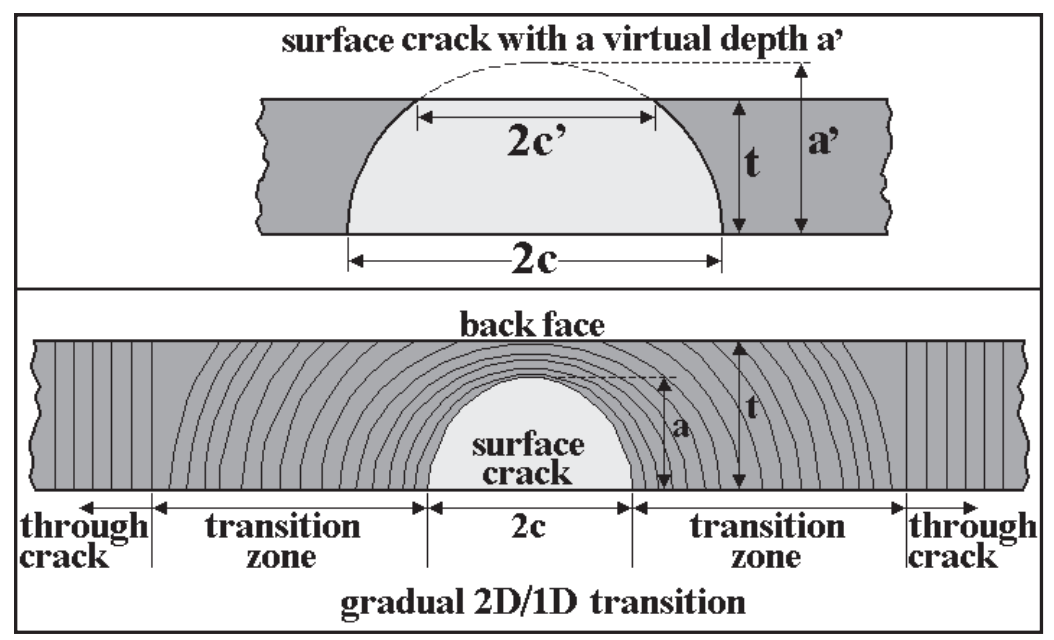

Figure 3: Gradual model for the 2D/1D surface-to-through-crack transition in the plate.

In other words, the $2 \mathrm{D} / 1 \mathrm{D}$ transition zone starts when the crack depth equals the specimen thickness $\left(a^{\prime}=a=t\right)$, and is assumed to end when the imaginary crack depth $a$ ' reaches $2.3 \cdot t$. Using this result, continuity of the width SIF expressions for the transitioning period, $K_{I}(c)$, and for the $1 \mathrm{D}$ crack growth regimen, $K_{I, 1 D}$, can be achieved replacing all occurrences of $c / t$ by a parameter

$$
r^{\prime} \equiv \alpha \cdot[c /(\alpha \cdot t)]^{\left(2.3-a^{\prime} / t\right) / 1.3}
$$

where $\alpha$ is the value of $c / t$ that satisfies $K_{I}(c)=K_{I, 1 D}$.

Note that $r^{\prime}=c / t$ in the beginning of the 2D/1D transition zone (when $a^{\prime}=t$ ), and $r^{\prime}=a$ when the transition ends and the crack finally becomes a 1D through-the-thickness crack with $a^{\prime}=2.3 \cdot t$. The application of this approach for the transition from surface (semi-elliptical) cracks to through-cracks is presented next.

\section{Transition from 2D semi-elliptical surface cracks to $1 \mathrm{D}$ through-cracks}

Newman and Raju modeled the SIF on the width and depth directions of surface cracks under uniaxial tension $\sigma$, respectively $K_{I}(c)$ and $K_{I}(a)$, by 


$$
\begin{aligned}
& K_{I}(c)=\sigma \sqrt{\pi c} \cdot F_{s, w} \cdot\left(M_{s} / \sqrt{Q}\right) \cdot(a / c) \cdot F_{s, c} \\
& K_{I}(a)=\sigma \sqrt{\pi a} \cdot F_{s, w} \cdot\left(M_{s} / \sqrt{Q}\right) \cdot F_{s, a}
\end{aligned}
$$

where $Q$ is the crack shape parameter, $F_{s, y}$ is the specimen width effect, $M_{s}$ is the back face magnification factor, and $F_{s, c}$ and $F_{s, a}$ are respectively the front surface effects on the width and depth directions, given by

$$
\begin{aligned}
& F_{s, w}(c / w, a / t)=\sqrt{\sec [(\pi c / 2 w) \cdot \sqrt{a / t}]} \\
& M_{s}\left(\frac{a}{c}, \frac{a}{t}\right)=\left\{\begin{array}{l}
1.13-0.09 \frac{a}{c}+\left(-0.54+\frac{0.89}{0.2+a / c}\right)\left(\frac{a}{t}\right)^{2}+\left(0.5-\frac{1}{0.65+a / c}+14\left(1-\frac{a}{c}\right)^{24}\right)\left(\frac{a}{t}\right)^{4}, a \leq c \\
\frac{c}{a}+0.04\left(\frac{c}{a}\right)^{2}+\left(\frac{c}{a}\right)^{4.5}\left(\frac{a}{t}\right)^{2}\left[0.2-0.11\left(\frac{a}{t}\right)^{2}\right], a>c
\end{array}\right. \\
& F_{s, c}(a / c, a / t)=\left\{\begin{array}{l}
1.1+0.35(a / t)^{2}, a \leq c \\
1.1+0.35(c / a)(a / t)^{2}, a>c
\end{array}\right. \\
& F_{s, a}=1.0
\end{aligned}
$$

For the 1D crack growth regimen, Tada [7] lists the SIF of a center-cracked plate as

$$
K_{I, 1 D}=\sigma \sqrt{\pi c} \cdot \sqrt{\sec (\pi c / 2 w)} \cdot\left[1-0.025(c / w)^{2}+0.06(c / w)^{4}\right]
$$

where $2 c$ and $2 w$ are the through-crack and plate widths. The last polynomial term in Eq. (10) improves its precision from $2.6 \%$ to better than $0.2 \%$. Therefore, comparing Eqs. (4) and (10), and noting that the only term in Eq. (4) that depends on $c / w$ is $F_{s, n}$, a modification for Eq. (6) is proposed

$$
F_{s, w}(c / w, a / t)=\sqrt{\sec [(\pi c / 2 w) \cdot \sqrt{a / t}]} \cdot\left[1-0.025[(c / w) \cdot \sqrt{a / t}]^{2}+0.06[(c / w) \cdot \sqrt{a / t}]^{4}\right]
$$

Eqn. (11) improves Newman-Raju's SIF solution to better model the plate width effect. The transition from a part-through 2D surface crack to a $1 \mathrm{D}$ through center crack is then modeled under uniaxial tension using Eqs. (4-5), (7-8), and (11), considering also $F_{s, a}=1.1$ to account for the back face becoming a free surface at $a=t$, resulting in

$$
\begin{aligned}
& K_{I}^{\prime}(c)=\sigma \sqrt{\pi c} \cdot F_{s, w}^{\prime} \cdot\left(M_{s}^{\prime} / \sqrt{Q^{\prime}}\right) \cdot(t / c) \cdot F_{s, c}^{\prime} \\
& K_{I}^{\prime}(a)=\sigma \sqrt{\pi t} \cdot F_{s, w}^{\prime} \cdot\left(M_{s}^{\prime} / \sqrt{Q^{\prime}}\right) \cdot F_{s, c}^{\prime}
\end{aligned}
$$

where the prime (') symbol denotes the expressions for the 2D/1D transition from part-through 2D to through $1 \mathrm{D}$ cracks (for $t<a^{\prime}=2.3 \cdot t$ ), and thus

$$
F_{s, w}^{\prime}(c / w)\left(\frac{c}{w}\right)=\sqrt{\sec (\pi c / 2 w)} \cdot\left[1-0.025(c / w)^{2}+0.06(c / w)^{4}\right]
$$




$$
\begin{aligned}
& M_{s}^{\prime}(c / t)=\left\{\begin{array}{l}
1.09-0.09 t / c+\frac{0.89}{0.2+t / c}-\frac{1}{0.65+t / c}+14(1-t / c)^{24}, \mathrm{c} \geq \mathrm{t} \\
c / t+0.04(c / t)^{2}+0.09(c / t)^{4.5}, \mathrm{c}<t
\end{array}\right. \\
& Q^{\prime}(c / t)=\left\{\begin{array}{l}
1+1.464(t / c)^{1.65}, \mathrm{c} \geq \mathrm{t} \\
1+1.464(c / t)^{1.65}, \mathrm{c}<\mathrm{t}
\end{array}\right. \\
& F_{s, c}^{\prime}(c / t)=\left\{\begin{array}{l}
1.45, \mathrm{c} \geq \mathrm{t} \\
1.1+0.35(c / t), \mathrm{c}<\mathrm{t}
\end{array}\right. \\
& F_{s, a}^{\prime}=1.1
\end{aligned}
$$

To guarantee continuity of the $K_{I}(c)$ expression, Eqs. (10) and (12) should be equivalent at the end of the 2D/1D transition zone (when $\left.a^{\prime}=2.3 \cdot t\right)$, resulting in

$$
\left.K_{I}^{\prime}(c) \equiv K_{I, 1 D}\right|_{a^{\prime}=2.3 t} \Rightarrow\left[M_{s}^{\prime}(c / t) / \sqrt{Q^{\prime}(c / t)}\right] \cdot(t / c) \cdot F_{s, c}^{\prime}(c / t)=1
$$

Notice that Eq. (19) is a function of $c / t$ only, having a unique solution for $c / t=1.23$. Therefore, if the ratio $c / t$ is replaced in Eqs. (12-18) by a function $r^{\prime}\left(c / t, a^{\prime} / t\right)$ that tends to 1.23 as $a^{\prime}$ tends to $2.3 \cdot t$, then continuity of the SIF is guaranteed. So, from Eq. (3), $r$ ' is expressed as

$$
r^{\prime}\left(c / t, a^{\prime} / t\right)=1.23 \cdot(c / 1.23 t)^{\left(2.3-a^{\prime} / t\right) / 1.3}
$$

and the SIF during the transitioning period is then modeled replacing $c / t$ by $r^{\prime}$ in Eqs. (12-18).

When the imaginary crack depth $a$ ' reaches $2.3 \cdot t$, Eq. (15) is then used to model the subsequent $1 \mathrm{D}$ crack growth. Fig. 4 plots the ratio between the transition and the 1D SIFs calculated using the proposed approach, to show their smooth transition.

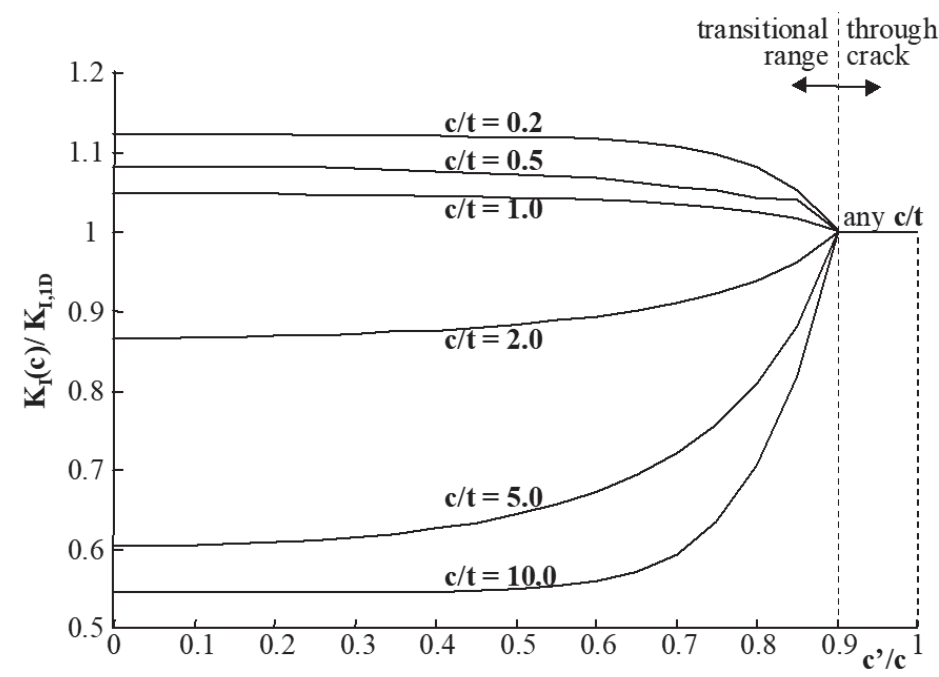

Figure 4: Ratio between the transition and 1D SIF calculated using the proposed approach.

Two main improvements are achieved using this approach. First, the effect of $c / t$ on $K_{I}(c)$ is much better modeled by Newman-Raju's equations than by the expressions used by Johnson. Second, continuity in the $K_{I}(c)$ function is guaranteed 
for the threshold from the transitional range to $1 \mathrm{D}$ growth through the use of Eq. (20). Notice in Fig. 4 that the function $r^{\prime}\left(c / t, a^{\prime} / t\right)$ only starts influencing significantly the calculated $K_{I}(c)$ when $c^{\prime} / c>0.5$. Fig. 5 plots the normalized stress intensity factor (also known as the geometry factor) in the width direction, calculated using the proposed approach. Notice the smooth transition between the surface and through-crack growth regimes, especially under high $c / w$ ratios.

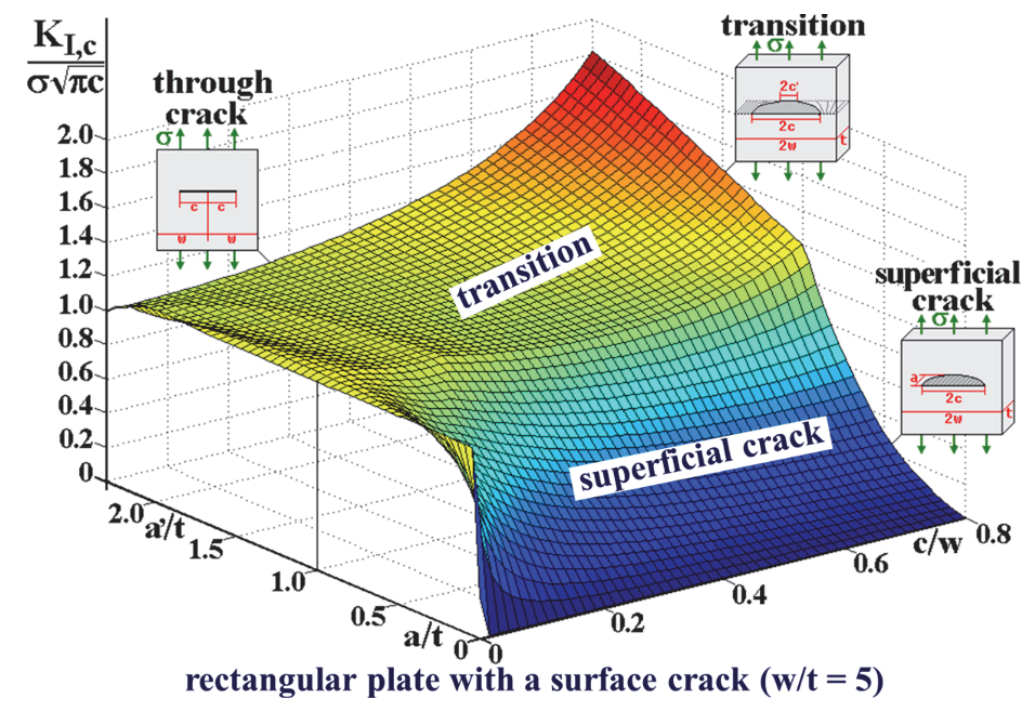

Figure 5: Geometry factor in the $c$ direction, for a surface crack on a rectangular plate with $w / t=5$.

The only remaining discontinuity in this model is due to the front surface effect on the depth direction, $F_{s, a .}$. However, since this discontinuity predicts a larger stress intensity factor as the crack enters the 2D/1D transition zone, false FCG retardation effects cannot cause calculation problems in fatigue life predictions. In the next section, the proposed approach to model the 2D/1D transition from part-through to through cracks is applied to corner (quarter-elliptical) cracks.

\section{Transition from $2 D$ corner quarter-elliptical cracks to $1 D$ through-cracks}

Newman and Raju modeled the SIFs on the width and depth directions of quart-elliptical corner cracks under uniaxial tension $\sigma$, respectively $K_{I}(c)$ and $K_{I}(a)$, by

$$
\begin{aligned}
& K_{I}(c)=\sigma \sqrt{\pi c} \cdot F_{q, w} \cdot\left(M_{q} / \sqrt{Q}\right) \cdot(a / c) \cdot F_{q, c} \\
& K_{I}(a)=\sigma \sqrt{\pi a} \cdot F_{q, w} \cdot\left(M_{q} / \sqrt{Q}\right) \cdot F_{q, a}
\end{aligned}
$$

where $Q$ is the crack shape parameter defined in Eq. (4), $F_{q, w}$ is the specimen width effect (modeled by Newman and Raju using the same function they used for surface cracks), $M_{q}$ is the back face magnification factor, and $F_{q, c}$ and $F_{q, a}$ are respectively the front surface effects on the width and depth directions, given by

$$
\begin{aligned}
& F_{q, w}(c / w, a / t)=\sqrt{\sec [(\pi c / 2 w) \cdot \sqrt{a / t}]} \\
& M_{q}\left(\frac{a}{c}, \frac{a}{t}\right)=\left\{\begin{array}{l}
1.08-0.03 \frac{a}{c}+\left(-0.44+\frac{1.06}{0.3+a / c}\right)\left(\frac{a}{t}\right)^{2}+\left(-0.5+0.25 \frac{a}{c}+14.8\left(1-\frac{a}{c}\right)^{15}\right)\left(\frac{a}{t}\right)^{4}, a \leq c \\
1.08 \frac{c}{a}-0.03\left(\frac{c}{a}\right)^{2}+\left(\frac{c}{a}\right)^{2.5}\left(\frac{a}{t}\right)^{2}\left[0.375-0.25\left(\frac{a}{t}\right)^{2}\right], a>c
\end{array}\right.
\end{aligned}
$$




$$
\begin{aligned}
& F_{q, c}\left(\frac{a}{c}, \frac{a}{t}\right)=\left\{\begin{array}{l}
1.08+0.4(a / t)^{2}, a \leq c \\
1.08+0.4(c / a)^{2}(a / t)^{2}, a>c
\end{array}\right. \\
& F_{q, a}\left(\frac{a}{c}, \frac{a}{t}\right)=\left\{\begin{array}{l}
1.08+0.15(a / t)^{2}, a \leq c \\
1.08+0.15(c / a)^{2}(a / t)^{2}, a>c
\end{array}\right.
\end{aligned}
$$

For the 1D crack growth regime, Tada [6] listed the SIF of a single edge-cracked plate as

$$
K_{I, 1 D}=\sigma \sqrt{\pi c} \cdot \sec \left(\frac{\pi c}{2 w}\right) \cdot\left(0.752+2.02 \frac{c}{w}+0.37\left(1-\sin \frac{\pi c}{2 w}\right)^{3}\right) \sqrt{\frac{2 w}{\pi c} \tan \frac{\pi c}{2 w}}
$$

where $c$ and $w$ are the through-crack and plate widths.

This expression is precise within $0.5 \%$ for any $a / c$ ratio, since it models the significant bending moment caused by the presence of the single edge crack, which exists even under pure uniaxial tension. Analogously to the surface crack modeling, a modification for Eq. (23) is proposed based on a comparison with Eq. (27)

$$
\begin{aligned}
F_{q, w}(c / w, a / t)=\sqrt{\sec [(\pi c / 2 w) \cdot \sqrt{a / t}]} . \\
\cdot\left[0.752+2.02 \frac{c}{w} \sqrt{\frac{a}{t}}+0.37\left(1-\sin \left(\frac{\pi c}{2 w} \sqrt{\frac{a}{t}}\right)\right)^{3}\right] \sqrt{\frac{2 w}{\pi c} \sqrt{\frac{t}{a}} \tan \left(\frac{\pi c}{2 w} \sqrt{\frac{a}{t}}\right)}
\end{aligned}
$$

The transition from $2 \mathrm{D}$ to $1 \mathrm{D}$ crack growth is then modeled considering $a=t$ in Eqs. (21-22), (24-26), and (28). Like for the surface cracks, the ratio $c / t$ is replaced by a function $r^{\prime}\left(c / t, a^{\prime} / t\right)$ that guarantees continuity between Eqs. (21) and (27). For corner quarter-elliptical cracks, the value of $\alpha$ in Eq. (3) is 1.73, and thus the function $r$ ' is defined by

$$
r^{\prime}=1.73 \cdot(c / 1.73 t)^{\left(2.3-a^{\prime} / t\right) / 1.3}
$$

The 2D/1D transition from part-through corner to through single-edge cracks $\left(t<a^{\prime}<2.3 \cdot t\right)$ is then modeled under uniaxial tension by

$$
\begin{aligned}
& K_{I}^{\prime}(c)=\sigma \sqrt{\pi c} \cdot F_{q, w}^{\prime} \cdot\left(M_{q}^{\prime} / \sqrt{Q^{\prime}}\right) \cdot\left(1 / r^{\prime}\right) \cdot F_{q, c}^{\prime} \\
& K_{I}^{\prime}(a)=\sigma \sqrt{\pi t} \cdot F_{q, w}^{\prime} \cdot\left(M_{q}^{\prime} / \sqrt{Q^{\prime}}\right) \cdot F_{q, a}^{\prime}
\end{aligned}
$$

Where

$$
\begin{aligned}
& F_{q, w}^{\prime}(c / w)=\sec \left(\frac{\pi c}{2 w}\right) \cdot\left[0.752+2.02 c / w+0.37\left(1-\sin \frac{\pi c}{2 w}\right)^{3}\right] \sqrt{\frac{2 w}{\pi c} \tan \frac{\pi c}{2 w}} \\
& M_{q}^{\prime}\left(r^{\prime}\right)=\left\{\begin{array}{l}
0.14+0.22 \cdot 1 / r^{\prime}+1.06 /\left(0.3+1 / r^{\prime}\right)+14.8\left(1-1 / r^{\prime}\right)^{15}, \mathrm{r}^{\prime} \geq 1 \\
1.08 r^{\prime}-0.03 \cdot r^{\prime 2}+0.125 \cdot r^{\prime 2.5}, \mathrm{r}^{\prime}<1
\end{array}\right.
\end{aligned}
$$




$$
\begin{aligned}
& Q^{\prime}\left(r^{\prime}\right)=\left\{\begin{array}{l}
1+1.464 \cdot\left(1 / r^{\prime}\right)^{1.65}, \mathrm{r}^{\prime} \geq 1 \\
1+1.464 \cdot r^{1.65}, \mathrm{r}^{\prime}<1
\end{array}\right. \\
& F_{q, c}^{\prime}\left(r^{\prime}\right)=\left\{\begin{array}{l}
1.48, \mathrm{r}^{\prime} \geq 1 \\
1.08+0.4 \cdot r^{\prime 2}, \mathrm{r}^{\prime}<1
\end{array}\right. \\
& F_{q, a}^{\prime}\left(r^{\prime}\right)=\left\{\begin{array}{l}
1.23, \mathrm{r}^{\prime} \geq 1 \\
1.08+0.15 \cdot r^{\prime 2},
\end{array} \mathrm{r}^{\prime}<1\right.
\end{aligned}
$$

When the imaginary crack depth a' reaches $2.3 \cdot t$, then Eq. (27) is used to model the subsequent 1D crack growth. Figs. 6 and 7 show the geometry factors of the SIF expressions in the $c$ and $a$ directions, calculated using the proposed expressions for corner quarter-elliptical cracks.

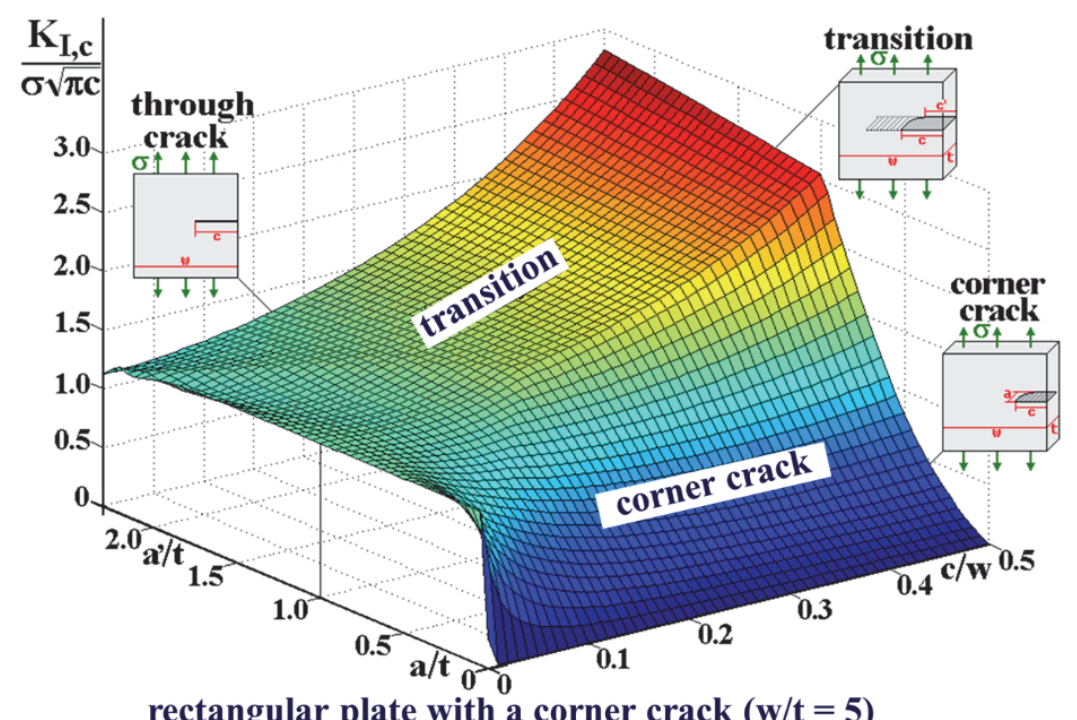

rectangular plate with a corner $\operatorname{crack}(w / t=5)$

Figure 6: Geometry factor in the $c$ direction, for a corner crack on a rectangular plate with $w / t=5$.

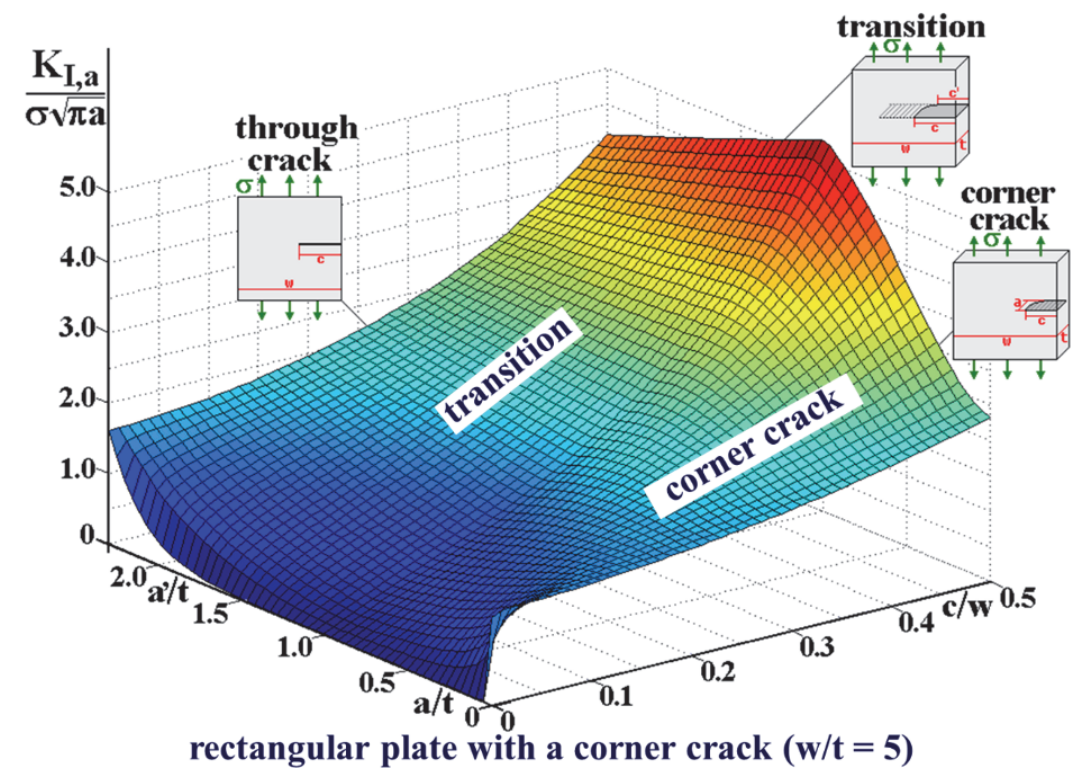

Figure 7: Geometry factor in the $a$ direction, for a corner crack on a rectangular plate with $w / t=5$, assuming $a=t$ if $a$ ' $>t$. 
Finally, consider an example where the SIFs in the width $K_{I}(c)$ and depth $K_{I}\left(a^{\text {a }}\right)$ directions have similar values (which happens e.g. for circular crack fronts), resulting in crack growth rates $d c / d N$ and $d a^{\prime} / d N$ that are approximately equal. Then, it is easy to show that if $c^{\prime}$ is much smaller than $c$, then the back face growth rate $d c^{\prime} / d N$ is such that

$$
\frac{d c^{\prime}}{d N}=\frac{d a^{\prime}}{d N} \cdot \frac{c^{2}}{c^{\prime} t} \cdot\left[1-\left(\frac{c^{\prime}}{c}\right)^{2}\right]^{3 / 2} \cong \frac{d a^{\prime}}{d N} \cdot \frac{c}{t} \cdot \frac{c}{c^{\prime}}>>\frac{d a^{\prime}}{d N} \cong \frac{d c}{d N} \Rightarrow \frac{d c^{\prime}}{d N}>>\frac{d c}{d N}
$$

Therefore, as long as $c$ is much smaller than $c$ (which happens in the beginning of the 2D/1D transition zone), Eq. (37) implies that the back face may experience a much larger growth rate than the front surface. This result is well in agreement with the "catch up effect" described by Grandt et al. [12], which is reproduced by the proposed interpolated equations.

\section{EXPERIMENTAL RESULTS}

7 his section presents data from FCG transition 2D-1D tests for two different materials: polycarbonate (PC) and 4340 steel. PC is a transparent and relatively tough polymer, so it can be used to obtain images from crack fronts while the fatigue crack grows. However, since it has long been recognized that its $d a / d N \times \Delta K$ behavior is very dependent on hard-to-control environmental parameters [25-30], the PC tests are considered here qualitatively only, since they could not yield reliable quantitative FCG rate data. Quantitative data are obtained by testing 4340 steel specimens. This material presents a well-defined $d a / d N \times \Delta K$ curve, thus such tests can also be used to validate fatigue analyses.

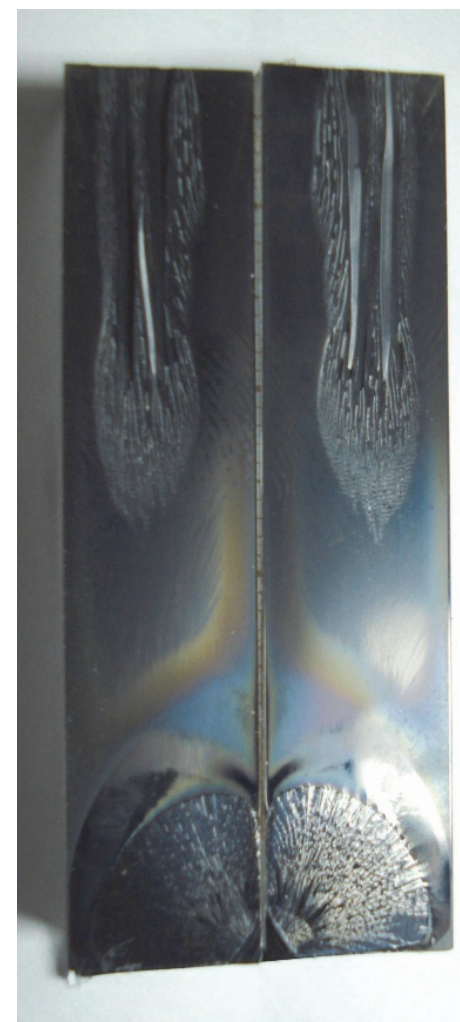

(a) $\mathrm{S} 1$

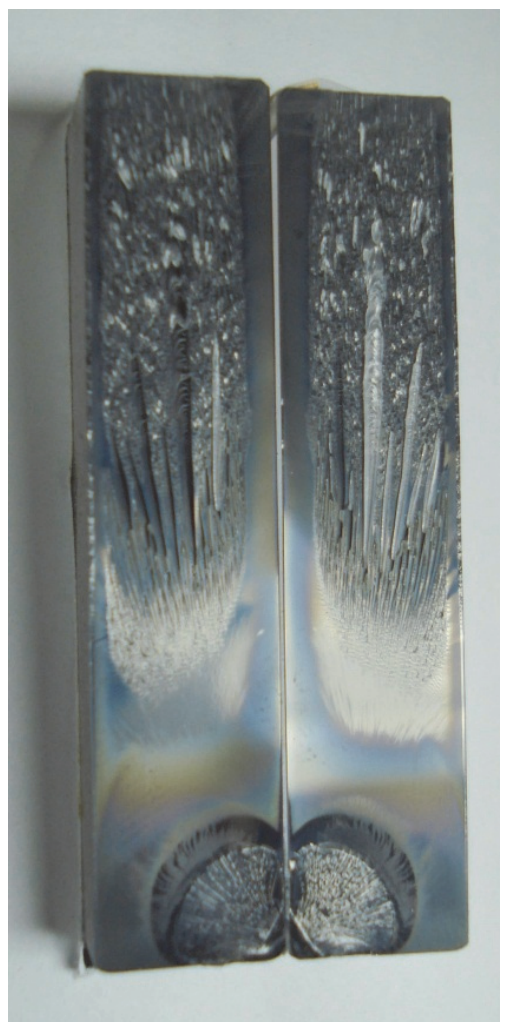

(b) S2

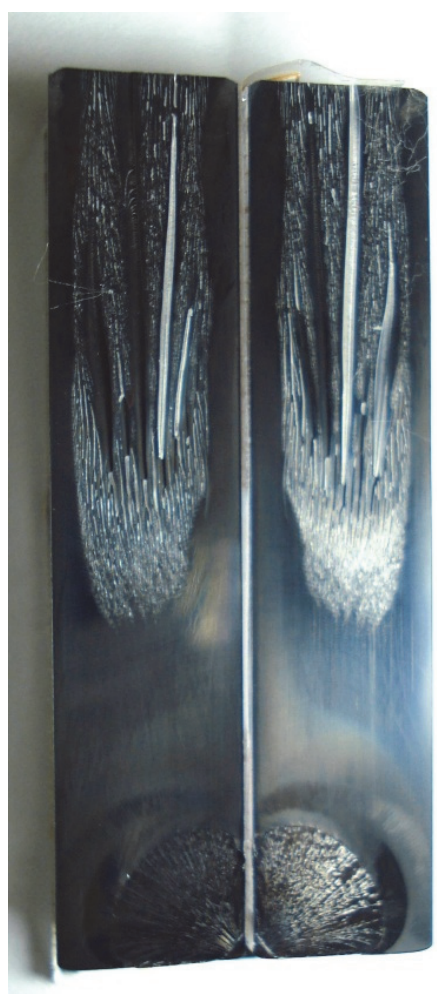

(c) $\mathrm{S} 3$

Figure 8: Crack propagation surfaces for the PC specimens named (a) S1, (b) S2, and (c) S3.

\section{Polycarbonate (PC)}

$365 \times 47 \times 10 \mathrm{~mm}$ plate PC specimens are tested under $R=\sigma_{\min } / \sigma_{\max }=0.1$ tension loads. First, a small initial triangular notch is machined on the corner of each specimen with a size between 1 and $2 \mathrm{~mm}$, to initiate and propagate a fatigue crack. This 
notch is easily made manually with a watchmaker's saw. Two digital cameras and one microscope are used to measure the FCG behavior during the tests. The first set of tests is performed under constant loads. However, the cracks propagated only in their 2D phase with $a / t<1$, so they did not enter the 2D-1D phase transition, as the fracture toughness was reached before that. Indeed, their SIFs increase relatively fast as the cracks grow and, at the same time, despite its relatively high toughness, the SIF range in the $d a / d \mathrm{~N} \times \Delta K$ PC curve is still very narrow (between $0.5-5 \mathrm{MPa} / \mathrm{m}$ ). Specimens used in this first set of tests are named S1, S2, and S3. The fatigue crack surfaces of these specimens after they broke are shown in Fig. 8. The load range values used in theses $P C$ tests are $\Delta P_{1}=5130 \mathrm{~N}, \Delta P_{2}=6840 \mathrm{~N}$ and $\Delta P_{3}=6000 \mathrm{~N}$, respectively.

To avoid this undesired behavior, a second set of PC specimens, named S4, S5, and S6, is tested under decreasing load ranges. However, even this precaution was not enough to eliminate experimental problems. Indeed, although their cracks did transition from 2D to 1D, high plasticity occurred on these specimen surfaces, creating non-negligible tunneling effects $[5,31]$, as shown in Fig. 9. Note that it is impossible to precisely define the crack sizes with such severely tunneled crack fronts.

So, a third set of PC tests is performed to properly simulate the desired 2D-1D crack transition, maintaining the SIF ranges low and approximately constant, $\Delta K_{I}(a)=\Delta K_{I}(c) \cong 1 \mathrm{MPa} \sqrt{\mathrm{m}}$, gradually reducing the load applied on the specimens as the cracks grew to obtain the desired well behaved 2D-1D transition. This testing strategy was successful and allowed the clear identification of the growing crack fronts.

Fig. 10 shows the resulting crack surfaces for the set of specimens named S7, S8 and S9. Fig. 11 is a mosaic that contains about 140 photomicrographs of successive crack fronts observed in specimen S9. Such well-defined beach marks helped to track the crack front lines as the crack gradually grew by fatigue. Notice in Fig. 11 that even though the initial $2 \mathrm{D}$ notch front is relatively far from a quarter-circular or elliptical shape, the following crack fronts quickly converge to such shapes, an indication that supports the claim stated in Fig. 1 that fatigue cracks apparently do like this well-behaved elliptical arc shape. Fig. 12 shows a sequence of images with different crack positions obtained in specimen S8. This test started with a frequency of $4 \mathrm{~Hz}$, which was reduced to $1 \mathrm{~Hz}$ and then to $0.1 \mathrm{~Hz}$.

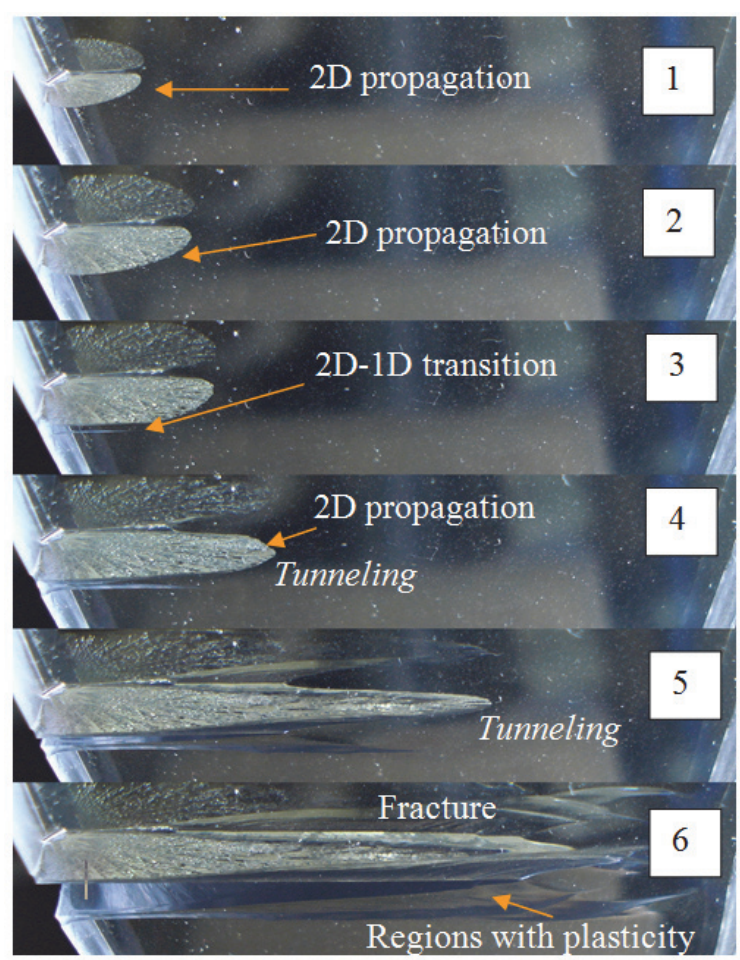

(a) S4

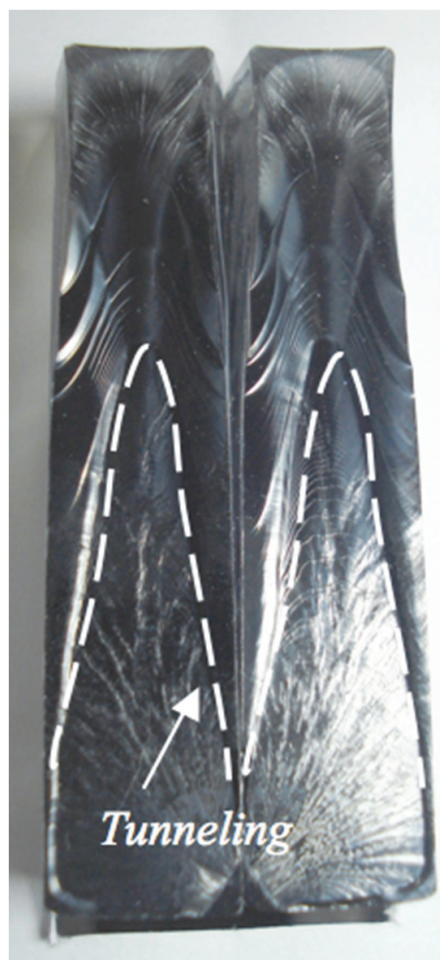

(b) S5

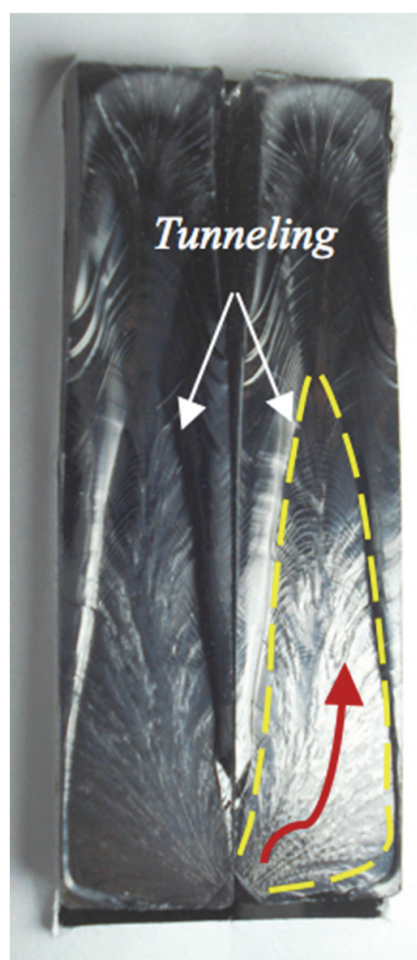

(c) S6

Figure 9: Crack propagation surfaces for the PC specimens named (a) S4, (b) S5, and (c) S6. 


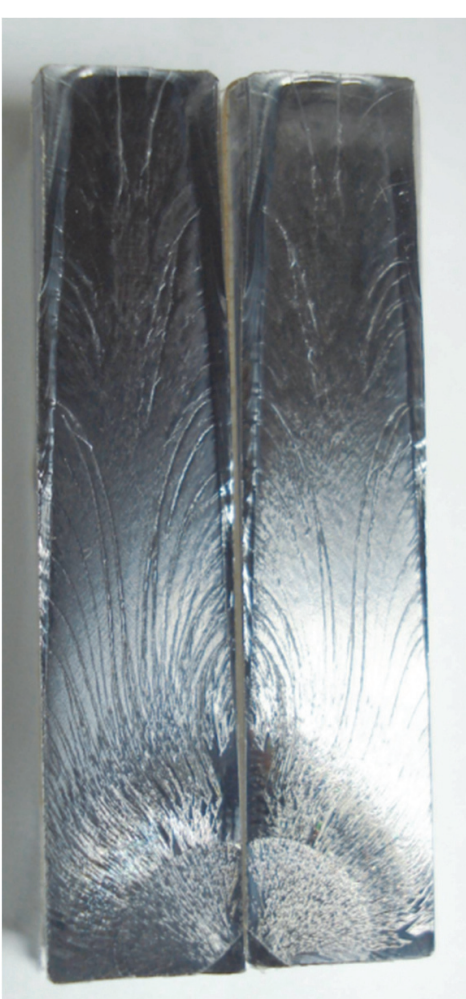

(a) S7

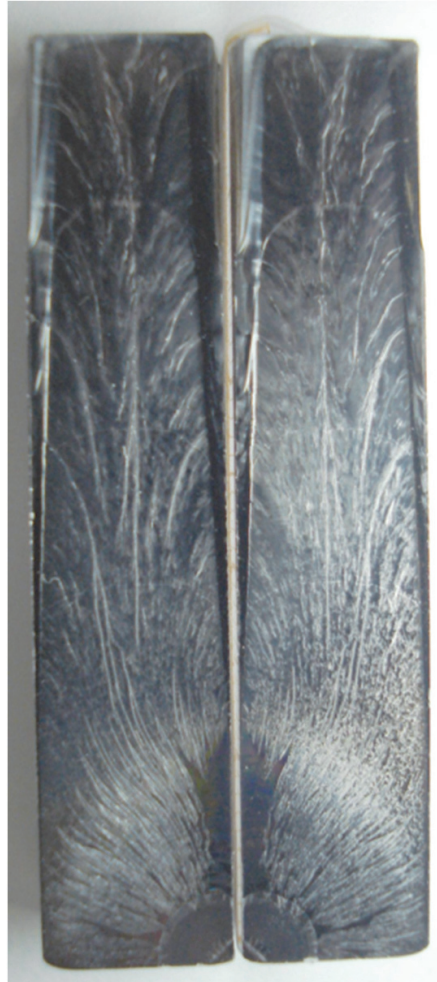

(b) $\mathrm{S} 8$

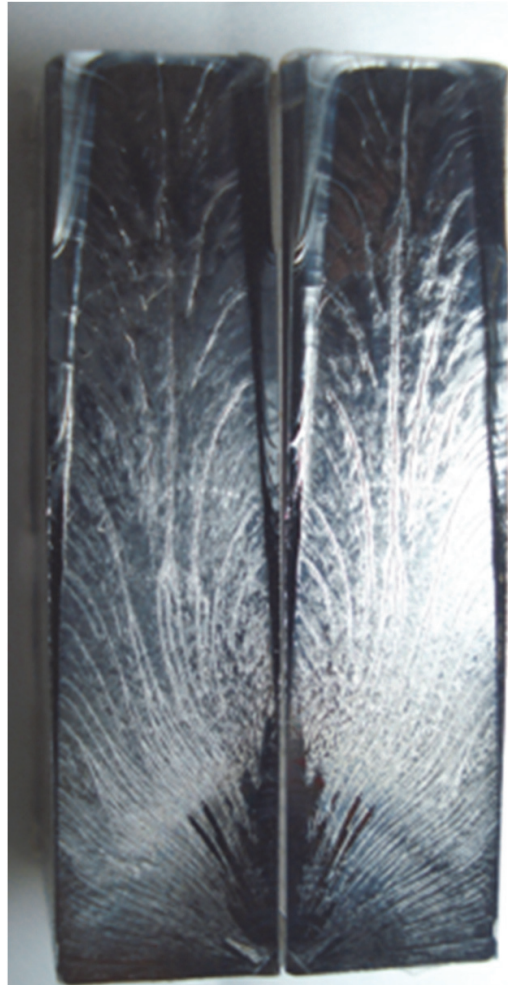

(c) S9

Figure 10: Crack propagation surfaces for the PC specimens named (a) S7, (b) S8, and (c) S9.
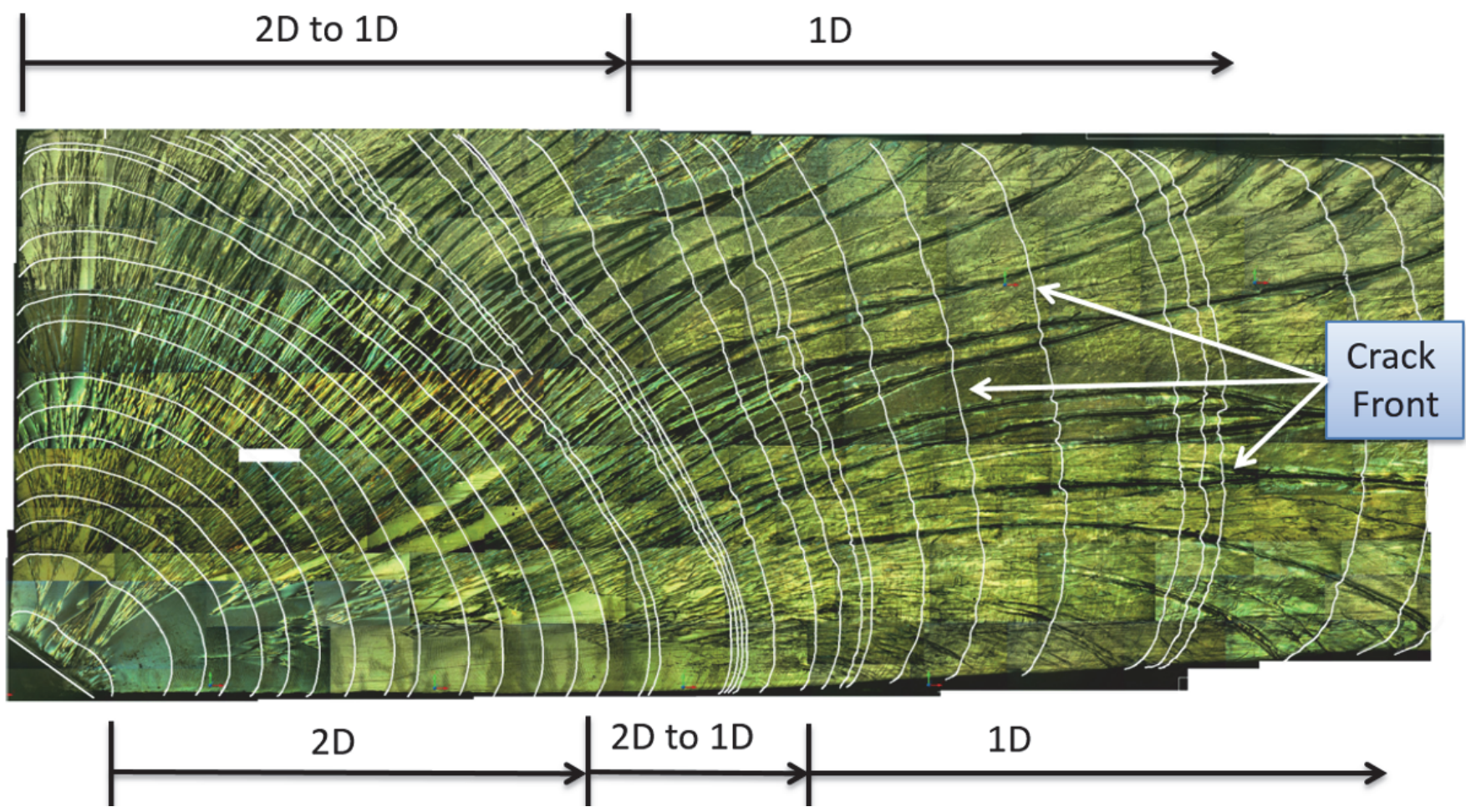

Figure 11: Detail of the successive crack fronts for the PC specimen named S9. 

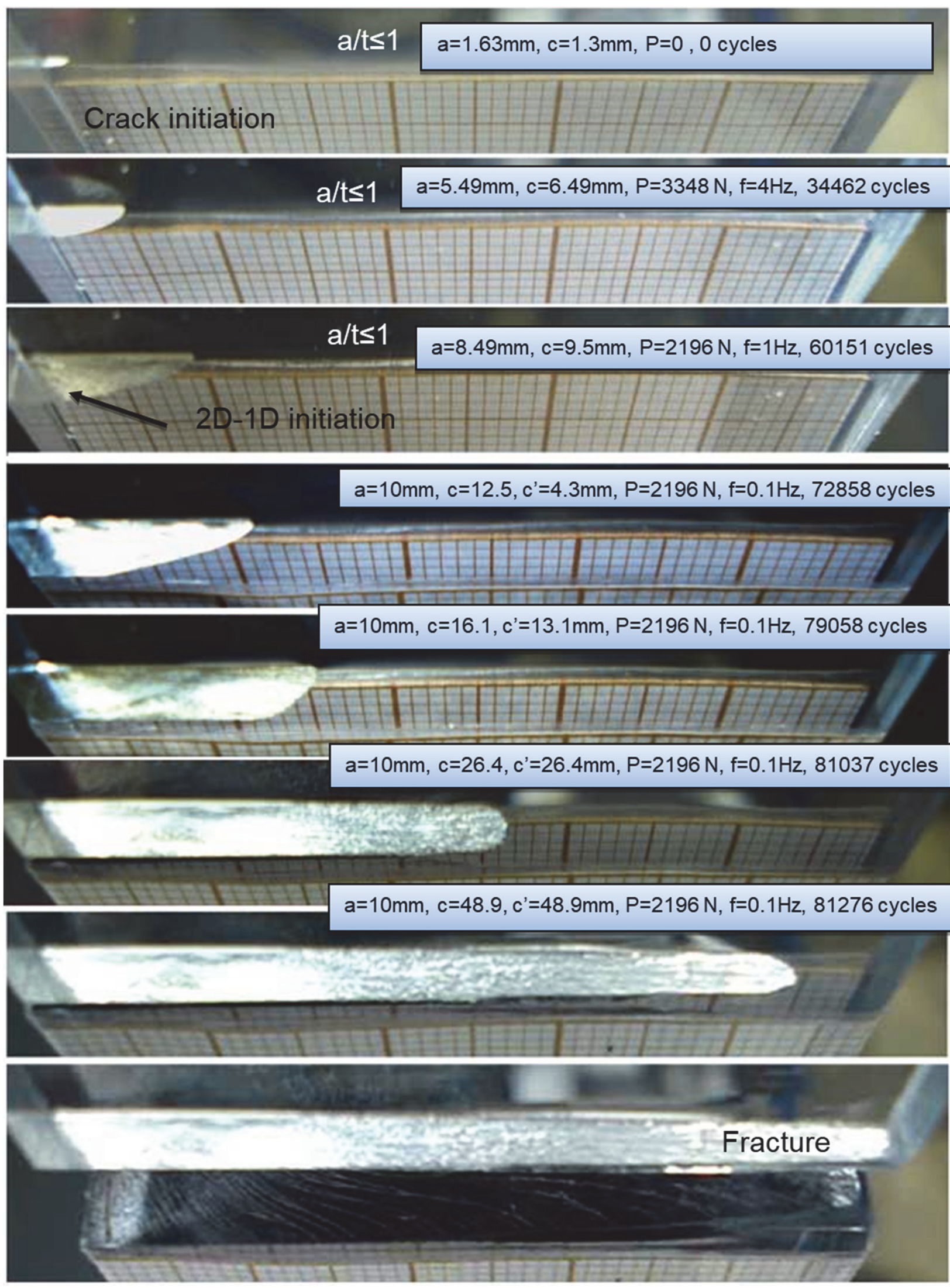

Figure 12: Sequence of images that show the fatigue crack propagation behavior measured in the PC specimen named S8. 


\section{Alloy Steel}

Due to the experimental difficulties faced when trying to reproduce smooth 2D-1D crack transitions in the PC specimens, additional FCG tests have been performed on similar $200 \times 21.5 \times 10 \mathrm{~mm}$ plate specimens made of annealed SAE 4340 steel. Initial triangular notches are also machined on the corner of these specimens, with initial sizes ranging from 2 to $3 \mathrm{~mm}$. Like in the PC tests, microscopes are used to monitor and measure the crack traces on the different faces of the opaque steel specimens.

FCG tests are performed at frequencies between 10 and $20 \mathrm{~Hz}$ in a $100 \mathrm{kN}$ computer-controlled servo-hydraulic testing machine, with a baseline SIF range between $\Delta K_{I} \cong 20 \mathrm{MPa} V_{\mathrm{m}}$ and $\Delta K_{I} \cong 60 \mathrm{MPa} ل_{\mathrm{m}}$, under $\mathrm{R}=0.1$. These SIF ranges lie in phase II of the $4340 d a / d N \times \Delta K$ curve, which can be well modeled by the Paris rule, avoiding issues with crack closure and short crack behaviors, see Fig. 13.

The tested SAE 4340 steel has yield strength $S_{Y}=377 \mathrm{MPa}$, ultimate strength $S_{U}=660 \mathrm{MPa}$, Young's modulus $E=205 \mathrm{GPa}$, and reduction in area $R A=52.7 \%$, measured according to ASTM E 8M-99 standard, and analyzed weight percent composition $0.37 \mathrm{C}, 1.53 \mathrm{Ni}, 0.64 \mathrm{Cr}, 0.18 \mathrm{Mo}, 0.56 \mathrm{Mn}, 0.14 \mathrm{Si}, 0.04 \mathrm{~S}, 0.035 \mathrm{P}$.

Its $d a / d N \times \Delta K$ data, obtained under $R=0.1$ and measured following ASTM E 647-99 procedures, see Fig. 13, can be well fitted by a Paris equation $d a / d \mathrm{~N}=2.5 \cdot 10^{-9} \cdot \Delta K^{2.48} \mathrm{~mm} /$ cycle.

Two 4340 alloy steel specimens are tested, named S10 and S11. To avoid early rupture during 2D-1D FCG transition, the applied load is gradually decreased to maintain a quasi-constant $\mathrm{SIF}$ range $\Delta K \cong 24 \mathrm{MPa} \sqrt{\mathrm{m}}_{\mathrm{m}}$.

Tabs. 1 and 2 show the load amplitudes applied on the specimens, the measured number of cycles and the corresponding crack lengths, according to the nomenclature adopted in Fig. 11. In these tables, the accumulated number of cycles (\#cycles) is relative to the event where the crack depth first reached the thickness of the plate specimen, i.e. when $a / t=1$.

Fig. 14 shows several fatigue crack fronts enhanced on the crack surfaces obtained after fracturing both specimens.

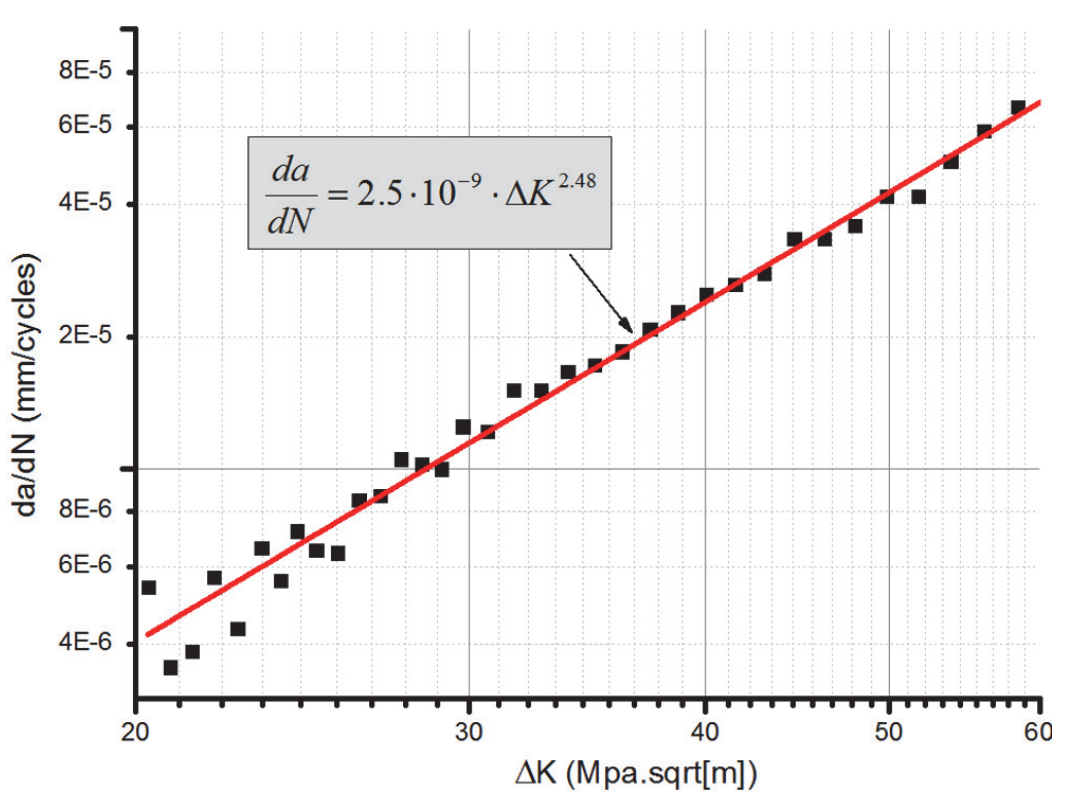

Figure 13: $d a / d N \times \Delta K$ data for the annealed 4340 alloy steel tested under $R=0.1$.

\section{Numerical Fatigue ANALYSES}

o compare the experimental data reported above with numerical fatigue life predictions, the proposed 2D to $1 \mathrm{D}$ transition equations are implemented on the software YiDDa (which means life in Portuguese). This versatile software has been developed to automate all traditional local approach methods used in fatigue design, namely the $S N$ (including IIW and DNV recommended practices for welded structures) and the $\varepsilon N$ for modeling crack initiation, and the $d a / d N$ for crack propagation [14]. In particular, two methods can be used to simulate 1D and 2D FCG problems under variable amplitude loads: the so-called $\Delta K_{\text {rms }}$ and the cycle-by-cycle methods (but only the latter can properly consider load sequence effects). For completeness purposes, these two methods are briefly discussed next. 


\begin{tabular}{crcc}
\hline $\begin{array}{c}\Delta P \\
(\mathrm{kN})\end{array}$ & $\begin{array}{c}\# \\
\text { cycles }\end{array}$ & $c(\mathrm{~mm})$ & $c^{\prime}(\mathrm{mm})$ \\
& 0 & 9.50 & 0.00 \\
6.21 & 32,911 & 9.80 & 1.00 \\
6.21 & 46,582 & 9.90 & 2.00 \\
6.21 & 65,511 & 10.00 & 3.00 \\
6.21 & 86,247 & 10.30 & 4.00 \\
6.21 & 110,782 & 10.50 & 5.00 \\
6.21 & 128,226 & 10.90 & 6.00 \\
6.21 & 143,143 & 11.20 & 7.00 \\
6.21 & 161,020 & 11.70 & 8.00 \\
6.21 & 173,165 & 12.10 & 9.00 \\
6.21 & 177,289 & 12.50 & 10.00 \\
6.21 & 184,763 & 13.00 & 11.00 \\
6.21 & 190,893 & 13.80 & 12.00 \\
6.21 & 195,997 & 14.50 & 13.00 \\
\hline
\end{tabular}

Table 1: Measured data for the S10 plate specimen, starting to count the \#cycles when the crack reaches its thickness

\begin{tabular}{crcc}
\hline$\Delta \mathrm{P}$ & $\begin{array}{c}\# \\
(\mathrm{kN})\end{array}$ & \multicolumn{1}{c}{$\mathrm{cycles}(\mathrm{mm})$} & $\mathrm{c}^{\prime}(\mathrm{mm})$ \\
& 0 & 8.50 & 0.00 \\
6.21 & 22,556 & 8.60 & 1.00 \\
6.21 & 72,218 & 8.70 & 2.00 \\
6.21 & 112,742 & 8.70 & 3.00 \\
6.21 & 168,555 & 8.70 & 4.00 \\
6.21 & 226,840 & 8.80 & 5.00 \\
6.21 & 280,313 & 9.10 & 6.00 \\
6.21 & 322,034 & 9.50 & 7.00 \\
6.21 & 355,595 & 9.90 & 8.00 \\
6.21 & 379,578 & 10.50 & 9.00 \\
6.21 & 395,228 & 11.10 & 10.00 \\
6.21 & 406,983 & 11.80 & 11.00 \\
5.28 & 415,666 & 12.70 & 12.10 \\
5.28 & 428,293 & 13.40 & 13.00 \\
5.28 & 435,471 & 14.20 & 14.00 \\
5.28 & 442,125 & 15.40 & 15.00 \\
5.28 & 446,086 & 16.20 & 16.00 \\
\hline
\end{tabular}

Table 2: Measured data for the S11 specimen, starting to count the \# cycles when the crack reaches its thickness.

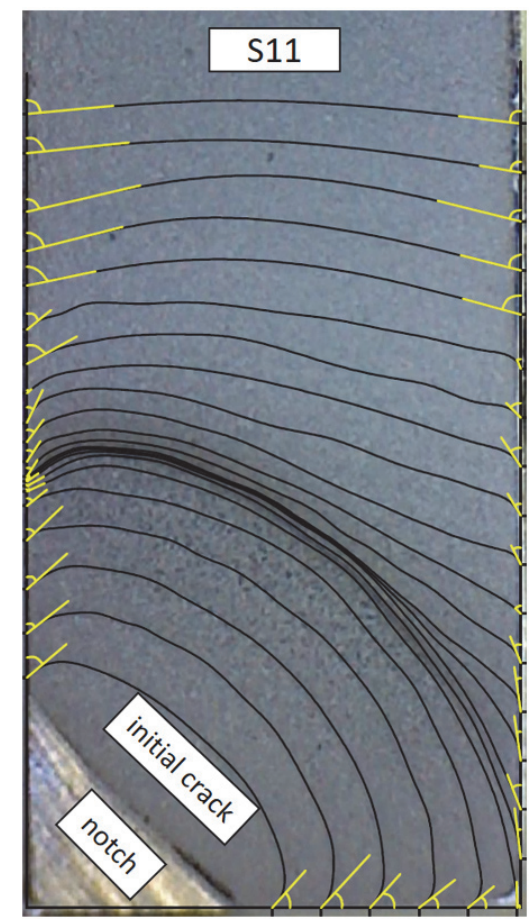

Figure 14: Successive crack fronts for the steel specimens S10 and S11.

The $\Delta K r m s$ method for $2 D$ cracks

The principal characteristic of 2D cracks is a non-homologous FCG behavior in two directions. Thus, although retaining the basic elliptical-like form, in general the 2D crack fronts tend to change shape from cycle to cycle, because their SIFs vary from point to point along their fronts. That is the main reason why $2 \mathrm{D}$ elliptic FCG problems can be a convenient 
approximation for many actual surface, corner, or internal cracks, since fractographic observations as those presented above support the idea that the successive crack fronts tend to achieve an approximately elliptical form and to stay approximately elliptical during their FCG. Therefore, it can be quite reasonable to assume when modeling such 2D cracks that their FCG just changes the shape of their fronts (given by the $a / c$ ratio between the ellipsis semi-axes, which quantifies how elongated the cracks are), while preserving their basic ellipsoidal geometry.

Since any ellipsis is completely defined by its two semi-axes, to model and predict the FCG behavior of such $2 \mathrm{D}$ elliptical cracks, including their shape changes, it is enough to calculate at each load cycle the lengths of the ellipsis axes $a$ and $c$, solving the coupled $d a / d \mathrm{~N}$ and $d c / d \mathrm{~N}$ propagation problems. Although laborious, this is not a particularly difficult task [10]. Hence, the simplest way to simulate the growth of 2D elliptical cracks, either under constant or under variable amplitude loadings, is to calculate their equivalent root mean square (rms) stress range $\Delta \sigma_{r m s}$ along the entire load history. The load history is then treated as a constant amplitude loading, a simplification that certainly cannot be used in the presence of rare but significant overloads, which can cause load interaction effects like FCG retardation or even arrest. Anyway, in this rms approach, the SIF range $\Delta K_{r m s}$ is initially calculated at the initial crack size $\left(a_{0}, c_{0}\right)$ by

$$
\Delta K_{r m s}\left(a_{0}\right)=\Delta \sigma_{r m s} \cdot\left[\sqrt{ }\left(\pi a_{0}\right) \cdot f_{a}\left(a_{0} / c_{0}, a_{0} / t, c_{0} / W\right)\right]
$$

Consequently, the number of cycles $N_{0}$ the crack takes to grow from $a_{0}$ to $a_{0}+\delta a$ is given by

$$
N_{0}=\delta a / F\left(\Delta K_{r m s}\left(a_{0}\right), R_{r m s}, \Delta K_{t h}, K_{c}, \ldots\right)
$$

where $\delta a$ is a small crack increment that must be specified by the fatigue analyst (e.g. 10 to $50 \mu \mathrm{m}$, numbers of the order of the resolution threshold of practical crack measurement methods in fatigue tests, can be a good choice both from the physical and from the numerical points of view). The associated SIF in the width direction $\Delta K_{\text {rms }}\left(c_{0}\right)$ can then be calculated from the proposed equations, to get the corresponding growth $\delta_{c}$ in the direction of the semi-axis $c$, given by

$$
\delta c_{0}=N_{0} \cdot F\left(\Delta K_{r m s}\left(c_{0}\right), R_{r m s}, \Delta K_{t h}, K_{c}, \ldots\right)
$$

The calculation process uses coupled interactions starting with $\Delta K_{r m s}\left(a_{1}\right)=\Delta K_{r m s}\left(a_{0}+\delta a\right)$ to obtain the corresponding number of cycles $N_{1}=\delta a / F\left(\Delta K_{r m s}\left(a_{1}\right), R_{r m s}, \Delta K_{t b}, K_{c}, \ldots\right)$ and then $\delta c_{1}=N_{1} \cdot F\left(\Delta K_{r m s}\left(c_{1}\right), R_{r m s}, \Delta K_{t b}, K_{c}, \ldots\right)$, where $c_{1}=c_{0}+\delta c_{0}$, and then starts over again. The calculation precision can be adjusted by the chosen $\delta a$ value. As these cracks usually have different values for $\Delta K(a)$ and $\Delta K(c)$, there are four distinct 2D propagation cases under constant amplitude loading:

1) $\Delta K\left(a_{0}\right)$ and $\Delta K\left(c_{0}\right)>\Delta K_{t b}$ : the crack propagates in both directions, changing shape at each $i$-th load cycle depending on the ratio $\Delta K\left(a_{i}\right) / \Delta K\left(c_{i}\right)$.

2) $\Delta K\left(a_{0}\right)>\Delta K_{t h}$ and $\Delta K\left(c_{0}\right) \leq \Delta K_{t b}$ : the crack grows only in the a (depth) direction, until its size is large enough to make $\Delta K\left(c_{0}\right)>\Delta K_{t b}$, when the problem reverts to Case 1 . There are, however, pathological cases in which $\Delta K(a)$ decreases with $a$, and in these cases a crack can start propagating to later on stop if it reaches $\Delta K(a) \leq \Delta K_{t b}$. Moreover, this Case 2 can be deceiving in inspections, since the trace of a surface crack can remain constant during millions of cycles, apparently hinting that it is inactive, when in fact it is growing toward the inside of the piece, until reaching $\Delta K\left(c_{0}\right)>\Delta K_{t h}$, when it starts to propagate laterally in a relatively fast rate [10].

3) $\Delta K\left(a_{0}\right) \leq \Delta K_{t h}$ and $\Delta K\left(c_{0}\right)>\Delta K_{t h}$ : the opposite of the previous case, with the crack only propagates in the $c$ (width) direction, which can happen e.g. in very deep and narrow surface cracks, or under applied bending stresses when the crack depth is near the neutral bending axis.

4) $\Delta K\left(a_{0}\right)$ and $\Delta K\left(c_{0}\right) \leq \Delta K_{t b}$ : the crack does not propagate.

The cycle-by-cycle method for $2 D$ cracks

In the cycle-by-cycle method, which is more versatile than the $\Delta K_{r m s}$ method since it can recognize and account for load sequence effects, in its simplest version associates each load event with the crack growth it would cause if it was the only one to load the piece. The FCG problem of $2 \mathrm{D}$ elliptical cracks can then be treated in a manner similar to that already discussed in the $\Delta K_{r m s}$ method: if in the $i$-th loading event the ellipsoidal crack has semi-axes $a_{i}$ and $c_{i}$, under

$$
\Delta K\left(a_{i}\right)=\Delta \sigma_{i} \cdot\left[\sqrt{ }\left(\pi a_{i}\right) \cdot f_{a}\left(a_{i} / c_{i}, a_{i} / t, c_{i} / W\right)\right] \text { and } \Delta K\left(c_{i}\right)=\Delta \sigma_{i} \cdot\left[\sqrt{ }\left(\pi a_{i}\right) \cdot f_{c}\left(a_{i} / c_{i}, a_{i} / t, c_{i} / W\right)\right]
$$


stress intensity ranges, and if $d a / d N=F\left(\Delta K, R, \Delta K_{t b}, K_{C}, \ldots\right)$ is the crack growth rule of the material, then the crack increment in this $i$-th $1 / 2$ cycle (obtained e.g. from the output of a sequential rainflow counter) is given by

$$
\begin{aligned}
& \delta a_{i}=(1 / 2) \cdot F\left(\Delta K\left(\Delta \sigma_{i}, a_{i}, f_{a}\right), R\left(\Delta \sigma_{i}, \sigma_{\max _{i}}\right), \Delta K_{t b}, K_{C}, \ldots\right) \\
& \delta c_{i}=(1 / 2) \cdot F\left(\Delta K\left(\Delta \sigma_{i}, a_{i}, f_{c}\right), R\left(\Delta \sigma_{i}, \sigma_{\text {max }_{i}}\right), \Delta K_{t b}, K_{C}, \ldots\right)
\end{aligned}
$$

The crack growth history is then calculated by the simultaneous solution of $\Sigma \delta a_{i}$ and $\Sigma \delta c_{i}$. As the crack increments $\delta a_{i}$ and $\delta c_{i}$ depend on both semi-axes $a_{i}$ and $c_{i}$, the coupled 2D growth is well characterized. Contrary to the $\Delta K_{\text {rms }}$ method, which as any statistics loses sequence effects, the cycle-by-cycle method can deal with load order effects, as long as appropriate crack retardation (or acceleration) models are introduced in Eqs. (42-43), see [10] for details.

\section{Comparison between Experimental and Numerical Results}

Figs. 15 and 16 compare experimental data and numerical predictions for the FCG behavior of the 4340 alloy steel specimens S10 and S11, respectively. Experimental data points plotted in these figures are listed in Tabs. 1 and 2, while the numerical results are represented as continuous lines. The numerical simulations are obtained by the cycle-by-cycle fatigue life prediction method outlined above, considering the load applied on each specimen using the proposed corner crack transition equations, the actual $d a / d N \times \Delta K$ curve measured for the material as well as its other properties, and the specific geometry of the specimens. The initial values of $\mathrm{c}$ adopted in these simulations are equal to the measured ones in the beginning of the transition phase, for a fair comparison neglecting possible previous accumulated errors in the 2D FCG predictions, since only the 2D/1D transition equations are evaluated here. Moreover, since all load decrease steps are very small during the tests, no FCG retardation models are needed in these simulations either.

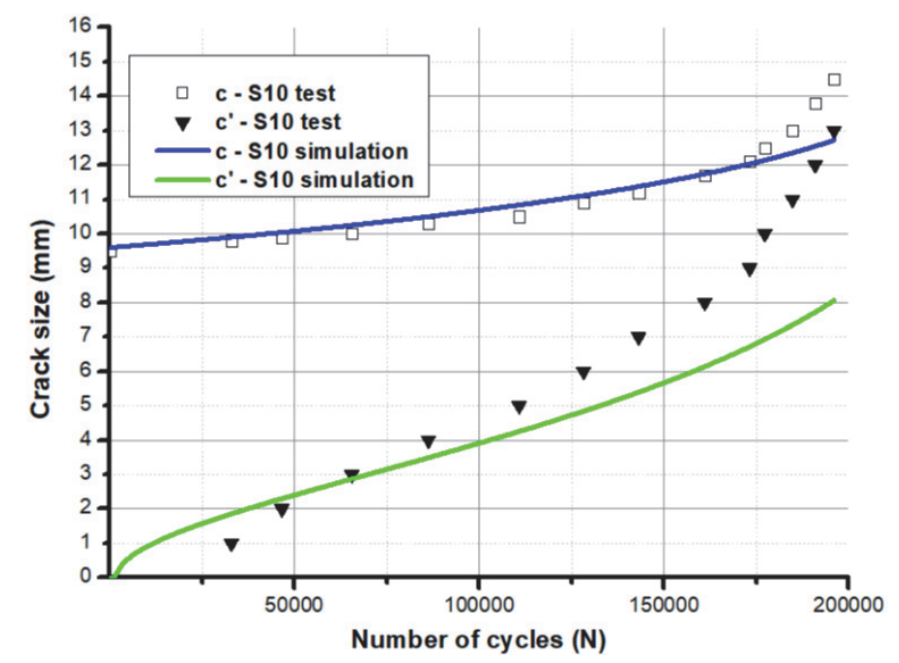

Figure 15: Measured and numerically predicted values for the crack lengths $c$ and $c^{\prime}$ at the front and the back face surfaces for the 4340 steel specimen S10, as a function of the number of cycles $\mathrm{N}$ since the beginning of the $2 \mathrm{D} / 1 \mathrm{D}$ transition phase.

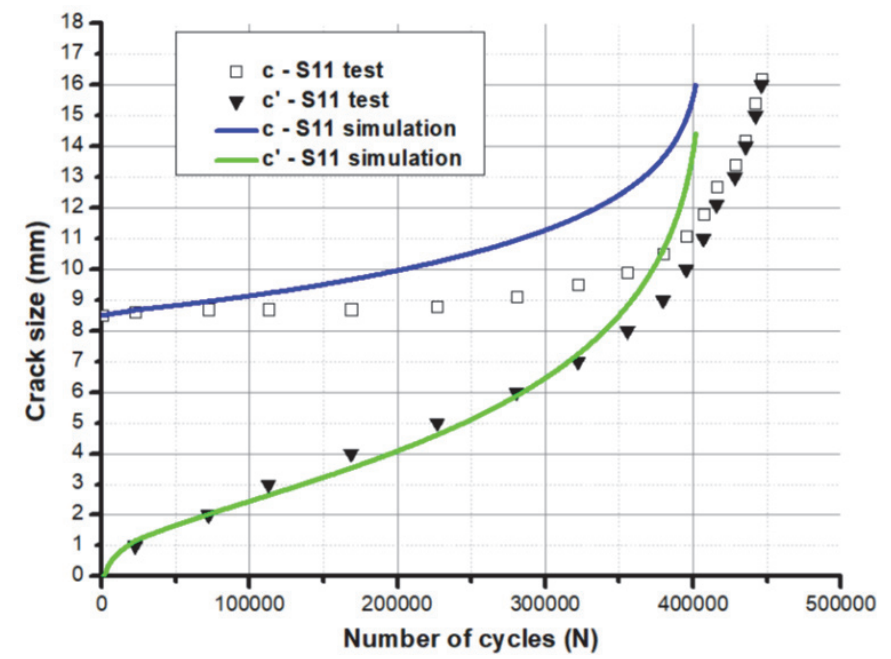

Figure 16: Measured and numerically predicted values for the crack lengths c and c' at the front and the back face surfaces for 4340 steel specimen S11, as a function of the number of cycles $\mathrm{N}$ since the beginning of the transition phase.

The S11 4340 steel specimen is tested until failure, which happened 453,594 cycles after the beginning of the 2D/1D transition. The simulated front and back face crack sizes after such applied cycles are $c=16.0 \mathrm{~mm}$ and $c^{\prime}=14.40 \mathrm{~mm}$, respectively a difference of $1.23 \%$ and $10.0 \%$ with respect to the experimental results, see Fig. 16 . For the S10 specimen, the final simulated front and back face crack sizes are $c=12.71 \mathrm{~mm}$ and $c^{\prime}=8,06 \mathrm{~mm}$, respectively a difference of $12.41 \%$ and $38.0 \%$ with respect to the experimental results, see Fig. 15. 


\section{CONCLUSIONS}

7 he transition of 2D part-through cracks (such as surface or corner flaws) to 1D through-cracks was modeled based on Newman-Raju's SIF equations for 2D elliptical cracks. The proposed interpolation equations were applied to describe the fatigue crack growth behavior of both surface and corner cracks on rectangular plates. The resulting continuous expressions were shown to better model not only the back face magnification and crack shape effects, but also the influence of the specimen width and front surface on the growth of part-through cracks. In addition, the proposed equations guarantee continuity of the SIF expressions between the transitioning period and the through-crack growth regime, as well as being able to reproduce the observed "catch up effect." Comparison with experimental results showed that the proposed equations are able to reasonably represent the global behavior of the 2D-1D crack transitions.

\section{REFERENCES}

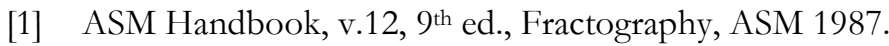

[2] Castro, J.T.P., Giassoni, A., Kenedi, P.P. (1998). Fatigue propagation of semi and quart-elliptical cracks in wet welds. J Braz Soc Mech Sci Eng 20, pp.263-277 (in Portuguese).

[3] Meggiolaro, M.A., Miranda, A.C.O., Castro, J.T.P., (2007). Short crack threshold estimates to predict notch sensitivity factors in fatigue. Int J Fatigue 29, pp. 2022-2031.

[4] Castro, J.T.P., Landim, R.V., Leite, J.C.C., Meggiolaro, M.A. (2015). Prediction of notch sensitivity effects in fatigue and EAC. Fatigue Fract Eng Mater Struct 38, pp. 161-179.

[5] Góes, R.C.O., Castro, J.T.P., Martha, L.F. (2014). 3D effects around notch and crack tips. Int J Fatigue 62, pp. 159170

[6] Pook, L.P. (1994). Some Implications of Corner Point Singularities. Eng Fracture Mech 48(3), pp. 367-378.

[7] Tada, H., Paris, P.C., Irwin, G.R. (2000). The Stress Analysis of Cracks Handbook, 3rd ed. Wiley.

[8] Murakami, Y. (1987). Stress Intensity Factors Handbook. Pergamon.

[9] Anderson, T.L. (2005). Fracture Mechanics, $3^{\text {rd }}$ ed., CRC.

[10] Castro, J.T.P., Meggiolaro, M.A. (2016). Fatigue Design Techniques v. 3: Crack Propagation, Temperature and Statistical Effects. CreateSpace 2016.

[11] Broek, D. (1989). The Practical Uses of Fracture Mechanics, Kluwer.

[12] Grandt, A.F., Harter, J.A., Heath, B.J. (1994). Transition of part-through cracks at holes into through-the-thickness flaws. ASTM STP 833, pp. 7-23.

[13] Rifani, A.I., Grandt, A.F. (1996). A fracture mechanics analysis of fatigue crack growth in a complex cross section. Eng Failure Analysis 3, pp. 249-265.

[14] Meggiolaro, M.A., Castro, J.T.P. (2010). Automation of the fatigue design under variable amplitude loading using the ViDa software. Int J Struct Integrity 1, pp. 94-103.

[15] Fawaz, S.A. (1997). Fatigue crack growth in riveted joints. Delft University Press.

[16] Johnson, W.S. (1979). Prediction of constant amplitude fatigue crack propagation in surface flaws. ASTM STP 687, pp. 143-155.

[17] Hall, L.R., Shah, R.C., Engstrom, W.L. (1974). Fracture and fatigue crack growth behavior of surface flaws and flaws originating at fastener holes. A.F.F.D. Laboratory.

[18] Newman Jr, J.C. (1979). A review and assessment of the stress-intensity factors for surface cracks. ASTM STP 687, pp. 16-46.

[19] Raju, I.S., Newman Jr, J.C. (1979). Stress-intensity factors for a wide range of semi-elliptical surface cracks in finitethickness plates. Eng Fract Mech 11, pp. 817-829.

[20] Newman Jr, J.C., Raju, I.S. (1983). Stress-intensity factor equations for cracks in three-dimensional finite bodies. ASTM STP 791, pp. 238-265.

[21] Newman Jr, J.C., Raju, I.S. (1984). Stress-intensity factor equations for cracks in three-dimensional finite bodies subjected to tension and bending loads. NASA TM-85793.

[22] Raju, I.S., Atluri, S.N., Newman Jr, J.C. (1988). Stress-intensity factors for small surface and corner cracks in plates. NASA TM-100599.

[23] Carpinteri, A., Brighenti, R., Spagnoli, A. (1988). Part-through cracks in pipes under cyclic bending. Nuclear Engineering and Design 185, pp. 1-10. 
[24] Carpinteri, A., Brighenti, R., Spagnoli, A. (2000). Fatigue growth simulation of part-through flaws in thick-walled pipes under rotary bending. Int J Fatigue 22, pp. 1-9.

[25] Hertzberg, R.W., Nordberg, H., Manson, J.A. (1970). Fatigue crack propagation in polymeric materials. J Mater Science 5, pp. 521-526.

[26] Kitagawa, M. (1974). Fatigue Crack Growth in Polycarbonate. Bulletin JSME 17, pp. 427-433.

[27] Martin, G.C., Gerberich, W.W. (1976). Temperature effects on fatigue crack growth in polycarbonate. J Mater Science 11, pp. 231-238.

[28] Radon, J.C., Chauhan, P., Culver, L.E. (1976). The influence of temperature and frequency on fatigue crack propagation in polymers. Colloid Polymer Science 254, pp. 382-388.

[29] Fraser, R.A.W., Ward, I.M. (1978). Temperature dependence of craze shape and fracture in polycarbonate. Polymer 19, pp. 220-224.

[30] Sehanobish, K., Haddaoui, N., Moet, A. (1993). Effect of thickness on ductile fatigue crack propagation in polycarbonate. J Mater Science 28, pp. 1360-1366.

[31] Zuo, J., Deng, X., Sutton, M.A. (2004). Crack Tunneling: Effect of Stress Constraint. ASME 2004 Int Mech Eng Congress Exposition, Anaheim, CA, USA. 